\title{
Synthesis of some novel $\alpha$-cyanoketene-n, s-acetals derived from secondary aliphatic amines and their use in pyrazole synthesis
}

\begin{abstract}
New $\alpha$-cyanoketene-N,S-acetals $2(\mathrm{a}-\mathrm{g})$ and $\beta$-dialkylamine- $\alpha$-cyanoacrylates $3(\mathrm{~g}-\mathrm{i})$ were synthesized in good to excellent yields by the reaction of ethyl 2-cyano-3,3bis(methylthio)acrylate 1 with secondary aliphatic amines (i.e., N-methylalkyl- and $\mathrm{N}$ ethylalkylamines), and pyrrolidine, in the presence of triethylamine, under reflux in ethanol, for $1-16 \mathrm{~h}$, depending on the amine used. Five $\mathrm{N}$-methylalkyl amines and pyrrolidine yielded exclusively mono-substituted $\mathrm{N}, \mathrm{S}$-acetals $2(\mathrm{a}-\mathrm{f})$ in good yields. On the other hand, Nethylbenzylamine gave a mixture of monosubstituted products including $\mathrm{N}, \mathrm{S}$-acetal $2 \mathrm{~g}$ in $35 \%$ yield and the unexpected product ethyl 3-[benzyl(ethyl)amino]-2-cyanoacrylate $3 \mathrm{~g}$ in $50 \%$ yield. N-Ethylcyclohexylamine and N-ethylbutylamine did not produce N,S-acetals and gave only the unexpected products ethyl 2-cyano-3-[cyclohexyl(ethyl)amino] acrylate $3 \mathrm{~h}$ and ethyl 3-[butyl(ethyl)amino]-2-cyanoacrylate $3 \mathrm{i}$ in good yields. The $\alpha$-cyanoketene-N,Sacetals $2(\mathrm{a}-\mathrm{f}), 2 \mathrm{j}$, and $2 \mathrm{k}$ underwent cyclization with the binucleophile hydrazine in ethanol under reflux to afford substituted pyrazoles $4(\mathrm{a}-\mathrm{f}), 4 \mathrm{j}$, and $4 \mathrm{k}$ in good yields.
\end{abstract}

Keyword: $\alpha$-Cyanoketene-N,S-acetals; Pyrazole derivatives; Secondary aliphatic amines. 